\title{
Infection with HIV and HCV enhances the release of fatty acid synthase into circulation: evidence for a novel indicator of viral infection
}

\author{
Gerard Aragonès ${ }^{1}$, Carlos Alonso-Villaverde ${ }^{2}$, Cristina Oliveras-Ferraros ${ }^{3,4}$, Raúl Beltrán-Debón ${ }^{1}$, Anna Rull1, \\ Fernando Rodríguez-Sanabria ${ }^{1}$, Jordi Camps ${ }^{1}$, Alejandro Vázquez Martín ${ }^{3,4}$, Javier A Menéndez ${ }^{3,4}$, Jorge Joven ${ }^{1 *}$
}

\begin{abstract}
Background: Fatty acid synthase (FASN) is an enzyme synthesized by the liver and plays an important role in lipogenesis. The present study aimed to investigate whether serum FASN concentration may provide a direct link between HIV and/or HCV viral infections and lipid metabolic disorders commonly observed in HIV/HCV-infected patients.

Methods: We evaluated serum FASN concentration in 191 consecutive HIV-infected patients in the absence or presence of HCV co-infection. For comparison, 102 uninfected controls were included. Metabolic and inflammatory phenotype was also compared with respect to the presence of HCV co-infection.

Results: Serum FASN concentration was significantly higher in HIV-infected patients than in healthy participants and HCV co-infected patients showed higher levels than those without co-infection. Levels were also affected by treatment regimen, but marginally influenced by virological variables. Insulin concentration was the sole variable among metabolic parameters that demonstrated a significant correlation with serum FASN concentrations. Serum alanine aminotransferase (ALT) values correlated significantly with serum FASN concentration and provided the best discrimination with respect to the presence or absence of HCV co-infection. In multivariate analysis, only ALT, monocyte chemoattractant protein-1 (MCP-1) and the presence of antiretroviral treatment regimen significantly contributed to explain serum FASN concentration in HIV/HCV co-infected patients.

Conclusion: Serum FASN concentration is significantly increased in HIV-infected individuals. The release of FASN into the circulation is further enhanced in patients who are co-infected with HCV. Subsequent studies should explore the usefulness of this indicator to monitor the effect of viral infections on disease progression and survival.
\end{abstract}

\section{Background}

The life expectancy of HIV-infected patients has dramatically improved with the use of antiretroviral therapies. Unfortunately, the spectrum of metabolic alterations and concurrent diseases, especially cardiovascular complications, is being expanded gradually and more than $10 \%$ of $\mathrm{HIV}$-infected patients experience life-threatening clinical manifestations that could be treated and/or prevented [1]. Although HIV-related metabolic alterations have been attributed, at least in part, to the use of

\footnotetext{
* Correspondence: jorge.joven@urv.cat

${ }^{1}$ Centre de Recerca Biomèdica, Hospital Universitari de Sant Joan, Institut d'Investigació Sanitària Pere Virgili (IISPV), Universitat Rovira i Virgili, Reus, Spain

Full list of author information is available at the end of the article
}

antiretroviral treatments, both dyslipidemia and insulin resistance can also be observed in treatment-naïve HIVinfected patients suggesting a metabolically deleterious role for the HIV infection itself $[2,3]$.

The mechanism by which HIV alters lipid metabolism in an infected cell is an issue largely unresolved; however, it was recently reported that HIV replication can significantly alter the expression of key cellular proteins closely involved in the maintenance of normal metabolic pathways [4,5]. Proteomic studies by Chan et al [4] initially reported upregulation of Fatty Acid Synthase (FASN) after HIV infection of cultured cells in vitro. Their findings causally associated this lipogenic enzyme - which remained undetectable in uninfected control 
cells - to the deregulation of the cell cycle after the HIV infection. Rasheed et al [5] further confirmed and expanded the notion that HIV replication alone (i.e. without any influence of antiviral drugs, or other human genetic factors) notably and specifically enhances production of FASN and other important proteins that mostly participate in lipid metabolism. FASN is also significantly up-regulated during infection with $\mathrm{HCV}[6,7]$, a frequent co-infection in HIV-patients [8]. We have therefore hypothesized that measurement of circulating FASN may provide a direct link between HIV and/or $\mathrm{HCV}$ viral infections and lipid metabolic disorders commonly observed in HIV/HCV-infected patients.

FASN, a $250-\mathrm{kDa}$ cytosolic multi-enzyme that is the major responsible for the de novo lipogenesis, functions normally in the liver whereas it is minimally expressed in most other normal human tissues [9]. FASN overexpression and the subsequent change in cell lipogenic phenotype may therefore be crucial in determining the fate of such cell in response to different stimuli. This notion has been already documented in human cancer pathogenesis. FASN is highly expressed in most human cancers and its inhibition leads to selective apoptotic death of cancer cells both in vitro and in vivo [10]. Cultured cancer cells can excrete immunoreactive FASN into the extracellular space and the detection of significant amounts of FASN in the blood of patients with breast, prostate, and ovarian cancer may also represent a potential biomarker for human cancer because serum FASN concentration is further increased in the late (metastatic) stages of human malignancies [11-14]. Although the ultimate mechanism regulating the extracellular release of FASN remains largely undefined $[14,15]$, we might envisage that serum FASN concentrations would become significantly altered in HIV-infected patients with respect to healthy controls and this could be related to the presence of $\mathrm{HCV}$ co-infection.

\section{Methods}

\section{Participants}

Patients included in this study attended the Hospital Universitari de Sant Joan in Reus, Spain. We performed a cross-sectional study in 191 consecutive HIV-infected patients who accepted the invitation to participate in the study and provided fully informed consent. Criteria for inclusion consisted of age greater than 18 years, no pre-existent AIDS-related opportunistic diseases and the absence of acute disease or clinical signs of inflammation. Patients with clinical or analytical evidence of renal insufficiency, cancer, neurological disorders or major liver damage were excluded. To avoid any possible bias, inclusion in the study was evaluated by personnel not directly responsible for these patients. The study was approved by the local Ethics Committee in accordance with the Declaration of Helsinki. For comparisons of selected variables we included a general populationbased control group of unrelated subjects $(n=102)$, free of HIV and HCV infection or any other inflammatory or metabolic alteration. Further details of the control group have been described elsewhere [16].

\section{Clinical and laboratory studies}

Detailed clinical characteristics of each subject were recorded and a thorough physical examination was performed during the interview. We recorded data regarding $\mathrm{HIV} / \mathrm{HCV}$ infections including opportunistic infections, mode of HIV transmission, CD4 cell count and $\mathrm{HIV} / \mathrm{HCV}$ viral loads, $\mathrm{HCV}$ genotypes, and details of the current and past antiretroviral therapy. Lipodystrophy was defined as the presence of body-fat changes that included subcutaneous lipoatrophy (hollow cheeks, prominent superficial veins in the limbs or flattening of the buttocks) and/or lipohypertrophy (central obesity, breast enlargement or dorsocervical fat pad). Data concerning classical cardiovascular risk factors and laboratory variables were also included. Blood pressure was determined according to standardized methods. Bodymass index was defined as weight $(\mathrm{kg}) /$ height $\left(\mathrm{m}^{2}\right)$. Fasting serum glucose, insulin, C-reactive protein, apolipoprotein A I, cholesterol, non-esterified fatty acids (NEFAs) and triglycerides were measured with the automatic analyzer LXi 725-Synchron (Beckman Coulter, Fullerton, California, USA) using enzymatic assays or chemiluminescent immunoassays. HDL-cholesterol and LDL-cholesterol levels were measured as described $[17,18]$. CD4+ and CD8 $+\mathrm{T}$ cells were counted using FACscan flow cytometry (Becton Dickinson, Madrid, Spain). Interleukin-6 (IL-6), interleukin-8 (IL-8) and monocyte chemoattractant protein-1 (MCP-1) were measured by a multiplex cytometric bead-based assay (FlowCytomix Multiplex; BenderMedsystems, Vienna, Austria) and were analyzed in an EPICS-XL-MCL flow cytometer (Beckman-Coulter, Fullerton, CA) following the manufacturer's protocol. Circulating levels of the extracellular form of FASN were measured by ELISA (FASgen Inc., Baltimore, MA).

\section{Statistical analysis}

Results are expressed as the mean (S.E.M) unless otherwise indicated. The Kolmogorov-Smirnov test was applied to check the normality of the variables. ANOVA was used to test the differences in continuous variables and the chi-square test was used for categorical variables. Non-parametric tests were used when appropriate. We performed multiple linear regression of FASN as a dependent variable; included in the model were classical variables and those variables for which the univariable analysis showed a $p$-value of at least 0.1 and collineality 
was assessed. All reported $p$-values are two-tailed and values greater than 0.05 denote statistical significance. The SPSS 17.0 package was used to perform the statistical analysis.

\section{Results}

Most HIV-infected patients in this study were smokers (80.6\%), 127 (66.5\%) were male, and their ages ranged from 29 years to 64 years. 114 (59.7\%) had undetectable HIV-1 viral load. The predominant cause of infection was intravenous drug abuse (59.2\%) and in the remaining patients, sexual factors were positively identified. Mean time since first serologic evidence of HIV infection was 4.29 (0.3) years. Obesity was not found in these patients but 47 (24.1\%) showed severe lipodystrophy. 115 (60.2) patients were co-infected with HCV. 64 patients were treated with protease inhibitor (PI)-containing regimen, 76 with non-nucleoside analogues reverse transcriptase inhibitors (NNRTI)-based therapy, and 51 currently not receiving any type of antiretroviral therapy for at least 6 months (Table 1).

Circulating levels of the extracellular form of FASN were systematically and significantly higher in HIVinfected patients than in healthy participants. Of note,

Table 1 Demographic and clinical characteristics of HIV-infected patients $(n=191)$

\begin{tabular}{lc}
\hline Characteristics & Values \\
\hline Age, years & $38.8(0.51)$ \\
Gender, male (\%) & $127(66.5)$ \\
BMI, kg/m & $22.93(0.26)$ \\
Current smokers, $\mathbf{n}(\%)$ & $154(80.6)$ \\
Lipodystrophy, $\mathbf{n}$ (\%) & $47(24.1)$ \\
Time of sero-prevalence, years & $4.29(0.3)$ \\
Risk factors for HIV, $\mathbf{n}(\%)$ & \\
Intravenous drug users & $113(59.2)$ \\
Heterosexual contact & $54(28.3)$ \\
Male homosexual contact & $24(12.5)$ \\
Treatment scheme, $\mathbf{n}$ (\%) & \\
Untreated & $51(26.7)$ \\
Non-nucleoside analogues & $76(39.8)$ \\
Protease inhibitors & $64(33.5)$ \\
Undetectable HIV-1 viral load ${ }^{\mathbf{a}}, \mathbf{n}$ (\%) & $114(59.7)$ \\
CD4+ T lymphocyte count, cells/mL & $459(22.8)$ \\
HCV co-infection, $\mathbf{n}$ (\%) & $115(60.2)$ \\
HCV genotypes, \% & \\
I II & 78.3 \\
IV & 3.8 \\
Log-HCV viral load, copies/mL & 14.9 \\
\hline Ialues are the mean and the & $3.89(1.14)$ \\
\hline
\end{tabular}

Values are the mean and the standard errors of the mean (S.E.M.), unless otherwise indicated.

a Limit of detection: 40 copies $/ \mathrm{mL}$. co-infection with $\mathrm{HCV}$ further significantly increased serum FASN concentration (Figure 1A). Moreover, circulating FASN levels were significantly affected by the presence of antiretroviral treatment. As shown in Figure 1B, untreated HIV-infected patients had higher levels of circulating FASN than those patients under antiretroviral therapy. However, serum FASN levels were marginally affected by the type of antiretroviral treatment. Both in the healthy control group and in the HIVinfected group we failed to observe significant associations between age or gender and serum FASN concentrations. However, a significant association was found in women with undetectable HIV viral load when HIVinfected patients were segregated according to the presence of HCV co-infection (Figure 1B). Gender-based differences in serum FASN concentration were also observed in patients undergoing an NNRTI-based antiretroviral treatment regimen (Figure 1C).

We then examined the metabolic phenotype in participants according to immunological and virologic variables such as $\mathrm{HIV} / \mathrm{HCV}$ viral loads as well as $\mathrm{HCV}$ genotype (Tables 2 and 3). Serum FASN concentration was not influenced by any virologic variable considered here but there was a significant $(\mathrm{p}=0.02)$ correlation $(\rho=0.28)$ between serum FASN concentration and lymphocyte T CD4+ count but only in those patients with detectable HIV viral load, suggesting that enhanced levels of extracellular FASN might come, at least in part, from lymphocyte T CD4+ T cells with active viral replication. Patients with lipodystrophy, in which distribution of $\mathrm{HCV}$ co-infected patients was identical to that of the whole group, also showed similar serum FASN concentrations $[9.7(3.2) \mu \mathrm{g} / \mathrm{L}]$ with respect to patients without such condition [10.4 (4.1) $\mu \mathrm{g} / \mathrm{L}]$. There was also a trend towards higher HOMA-IR values in HCV co-infected patients which was significantly altered by NNRTIregimen treatment and that positively correlated with serum FASN concentrations. HIV infection caused a significant and deleterious effect on HDL-cholesterol, apolipoprotein $\mathrm{AI}$ and triglycerides concentrations irrespective of $\mathrm{HCV}$ co-infection and treatment regimen in comparison with the healthy group. However, we failed to identify statistically significant changes in serum NEFAs concentrations among patients with $\mathrm{HCV}$ co-infection or among patients without co-infection.

Assessed inflammatory biomarkers were consistently elevated in HCV co-infected patients with respect to healthy participants, although the differences were not statistically significant for serum IL-8. Serum MCP-1 and CRP concentrations were significantly increased in HIV-infected patients irrespective to antiretroviral treatment, while co-infection did not result in further differences (Figure $2 \mathrm{~A}$ and $2 \mathrm{~B}$ ). We could not discriminate serum IL- 8 and IL- 6 concentrations of the control 


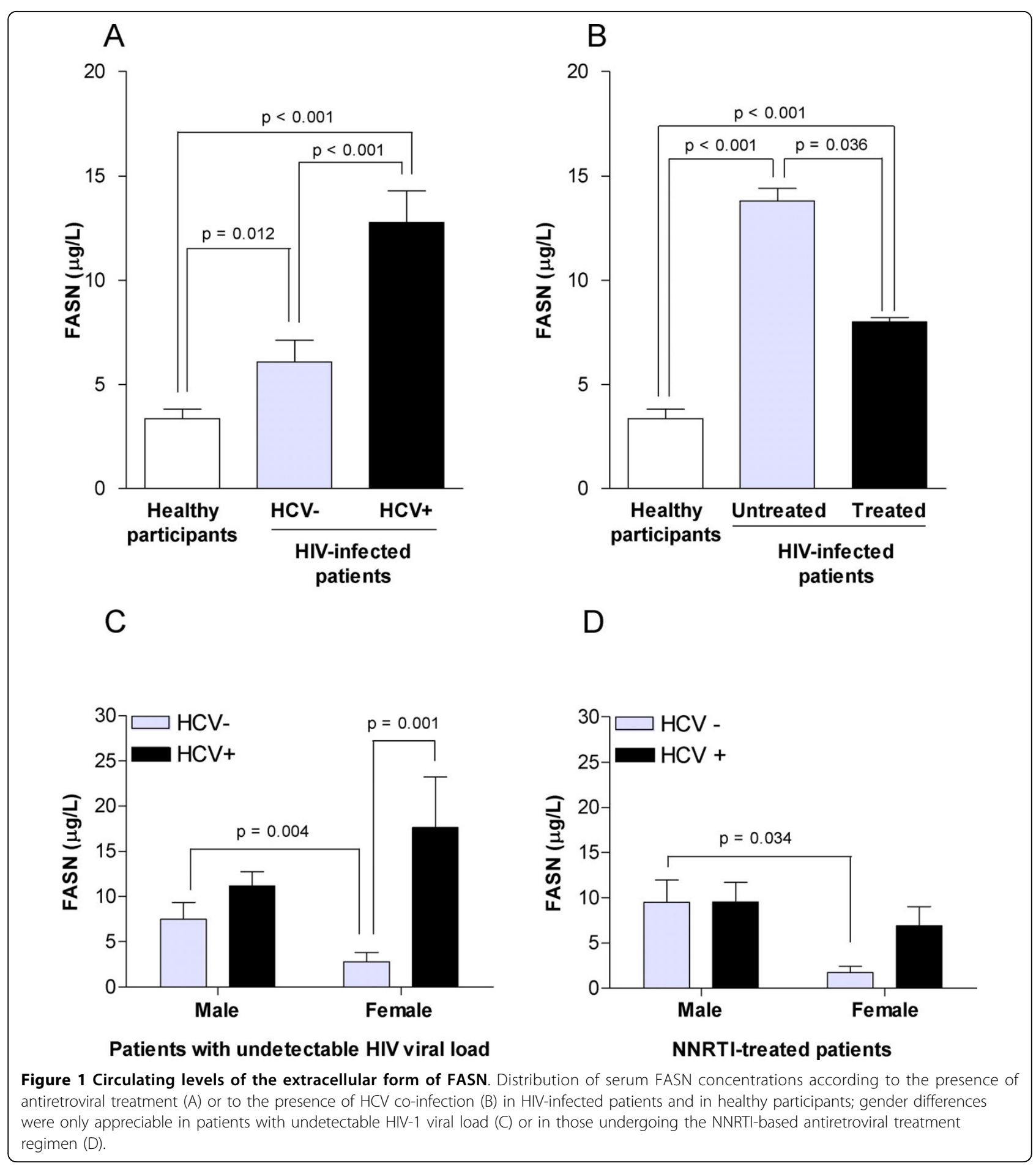

group from those of non-co-infected patients (Figure 2C and 2D). We also found significant correlations between serum MCP-1 and serum FASN concentrations that were not evident for the serum CRP concentration (Figure 3A and 3B). However, serum MCP-1 concentration was not correlated with any virological parameter above mentioned.
Among variables measured to ascertain the metabolic phenotype, only the serum insulin concentration showed a significant correlation with serum FASN, an association that was significant in both co-infected and nonco-infected patients (Figure 3C). As expected, serum aminotransferases were significantly higher in $\mathrm{HCV}$ co-infected patients, suggesting possible hepatic cellular 
Table 2 Metabolic profile of healthy participants and HIV-infected patients segregated according to HCV co-infection and HIV-1 viral load

\begin{tabular}{|c|c|c|c|c|c|}
\hline & \multirow{3}{*}{$\begin{array}{l}\text { Control group } \\
\qquad(n=102)\end{array}$} & \multicolumn{4}{|c|}{ HIV-infected patients } \\
\hline & & \multicolumn{2}{|c|}{ Non-HCV co-infected group } & \multicolumn{2}{|c|}{ HCV co-infected group } \\
\hline & & $\begin{array}{c}\mathrm{VL}<40 \text { copies } / \mathrm{mL} \\
(\mathrm{n}=47)\end{array}$ & $\begin{array}{c}\mathrm{VL}>40 \text { copies } / \mathrm{mL} \\
(\mathrm{n}=29)\end{array}$ & $\begin{array}{c}\mathrm{VL}<40 \text { copies } / \mathrm{mL} \\
(\mathrm{n}=67)\end{array}$ & $\begin{array}{c}\mathrm{VL}>40 \text { copies } / \mathrm{mL} \\
(\mathrm{n}=48)\end{array}$ \\
\hline FASN, $\mu \mathrm{g} / \mathrm{L}$ & $3.36(0.92)$ & $5.83(1.34)^{\mathrm{a}}$ & $5.08(1.74) *$ & $12.69(2.01)^{c}$ & $14.41(2.91)^{c}$ \\
\hline NEFA, mmol/L & $0.65(0.04)$ & $0.62(0.06)$ & $0.64(0.06)$ & $0.63(0.04)$ & $0.61(0.05)$ \\
\hline Glucose, $\mathrm{mmol} / \mathrm{L}$ & $4.96(0.16)$ & $5.61(0.20)^{c}$ & $5.2(0.14)^{b}$ & $5.42(0.12)^{c}$ & $5.16(0.10)^{b}$ \\
\hline Insulin, pmol/L & $64.6(6.59)$ & $69.22(9.68)$ & $47.95(6.11)^{a_{1} *}$ & $84.40(10.79)^{a}$ & $76.31(11.82)$ \\
\hline HOMA-IR & $1.15(0.20)$ & $1.33(0.18)$ & $0.92(0.14)^{a_{1} *}$ & $1.64(0.22)^{\mathrm{a}}$ & $1.48(0.25)$ \\
\hline Cholesterol, $\mathrm{mmol} / \mathrm{L}$ & $5.27(0.12)$ & $5.52(0.19)$ & $5.14(0.23)$ & $4.74(0.15)^{c}$ & $4.41(0.16)^{c}$ \\
\hline HDL-cholesterol, $\mathrm{mmol} / \mathrm{L}$ & $1.36(0.03)$ & $1.24(0.09)^{\mathrm{a}}$ & $1.15(0.08)^{b}$ & $1.21(0.05)^{b}$ & $1.07(0.05)^{c_{1} *}$ \\
\hline LDL-cholesterol, mmol/L & $3.19(0.79)$ & $3.28(0.17)$ & $2.96(0.17)$ & $2.71(0.13)^{c}$ & $2.38(0.13)^{c}$ \\
\hline Triglyceride, mmol/L & $1.27(0.9)$ & $3.00(0.47)^{c}$ & $3.11(1.01)$ & $2.04(0.18)^{c}$ & $3.24(1.09)^{c}$ \\
\hline Apolipoprotein Al, g/L & $1.69(0.05)$ & $1.44(0.05)^{c}$ & $1.26(0.04)^{c_{1} * *}$ & $1.40(0.03)^{c}$ & $1.33(0.04)^{c}$ \\
\hline Alanine aminotransferase, $\mu \mathrm{Kat} / \mathrm{L}$ & $0.46(0.02)$ & $0.45(0.03)$ & $0.51(0.04)$ & $0.98(0.11)^{c}$ & $0.97(0.11)^{c}$ \\
\hline Aspartate aminotransferase, $\mu \mathrm{Kat} / \mathrm{L}$ & $0.41(0.02)$ & $0.41(0.03)$ & $0.47(0.08)$ & $0.88(0.09)^{c}$ & $0.88(0.99)^{c}$ \\
\hline
\end{tabular}

Values are the mean and the standard error of the mean (S.E.M.).

VL indicates HIV-1 viral load; HOMA-IR is homeostasis model assessment-estimated insulin resistance; NEFA is non-esterificated fatty acids.

${ }^{\mathrm{a}} \mathrm{P}<0.05{ }^{\mathrm{b}} \mathrm{P}<0.01$ and $^{\mathrm{c}} \mathrm{P}<0.001$ with respect to control group; ${ }^{*} \mathrm{P}<0.05$ and ${ }^{* *} \mathrm{P}=0.006$ with respect to patients with $\mathrm{VL}<40$ copies/mL in the corresponding group

leakage or damage (Table 2). Moreover, serum alanine aminotransferase (ALT) values provided the best discrimination with respect to the presence or absence of $\mathrm{HCV}$ co-infection and correlated significantly with serum FASN concentration irrespective of the condition of co-infection (Figure 4). In multivariate analysis only ALT, MCP-1 and the presence of treatment regimen significantly contributed to explain serum FASN concentration in HIV-patients co-infected with $\mathrm{HCV}$.
This relationship, however, was not maintained in patients not infected by HCV (Table 4).

\section{Discussion}

It is currently considered that during metastasic progression of human malignancies the intracellular FASN is up-regulated and over-expressed and the excess is finally released from the cytosol to the circulation in a stage-related manner [11-14]. Using a proteomics

Table 3 Metabolic profile of HIV-infected patients segregated according to HCV co-infection and antiretroviral therapy

\begin{tabular}{|c|c|c|c|c|c|c|}
\hline & \multicolumn{3}{|c|}{ Non-HCV co-infected group } & \multicolumn{3}{|c|}{ HCV co-infected group } \\
\hline & $\begin{array}{l}\text { Untreated } \\
(n=19)\end{array}$ & $\begin{array}{c}\text { NNRTI } \\
(n=32)\end{array}$ & $\begin{array}{c}\mathrm{PI} \\
(n=25)\end{array}$ & $\begin{array}{l}\text { Untreated } \\
(n=32)\end{array}$ & $\begin{array}{l}\text { NNRTI } \\
(n=44)\end{array}$ & $\begin{array}{c}\mathrm{PI} \\
(n=39)\end{array}$ \\
\hline FASN, $\mu \mathrm{g} / \mathrm{L}$ & $5.14(2.10)$ & $7.40(1.81)$ & $4.15(1.00)$ & $20.01(4.0)$ & $8.64(1.51)^{b}$ & $11.75(2.41)^{a}$ \\
\hline NEFA, mmol/L & $0.53(0.07)$ & $0.63(0.07)$ & $0.77(0.1)$ & $0.65(0.06)$ & $0.67(0.05) *$ & $0.52(0.04)$ \\
\hline Glucose, $\mathrm{mmol} / \mathrm{L}$ & $5.21(0.20)$ & $5.77(0.29) *$ & $5.09(0.09)$ & $5.13(0.13)$ & $5.62(0.19)^{a}$ & $5.21(011)$ \\
\hline Insulin, pmol/L & $41.91(7.1)$ & $70.74(13.4)^{\mathrm{a}}$ & $62.23(8.6)^{a}$ & $71.35(11.2)$ & $103.2(19.8)$ & $72.24(10.7)$ \\
\hline HOMA-IR & $0.80(0.16)$ & $1.38(0.27)^{\mathrm{a}}$ & $1.14(0.16)$ & $1.41(0.25)$ & $2.06(0.42)$ & $1.36(0.21)$ \\
\hline Cholesterol, mmol/L & $4.59(0.24)$ & $5.34(0.23)^{a, *}$ & $6.10(0.28)^{c}$ & $4.41(0.19)$ & $4.67(0.23)$ & $4.7(0.16)$ \\
\hline HDL-cholesterol, $\mathrm{mmol} / \mathrm{L}$ & $1.18(0.09)$ & $1.30(0.12)$ & $1.18(0.10)$ & $1.17(0.07)$ & $1.20(0.05) *$ & $1.09(0.6)$ \\
\hline LDL-cholesterol, mmol/L & $2.69(0.22)$ & $3.10(0.20) *$ & $3.59(0.23)^{\mathrm{a}}$ & $2.57(0.15)$ & $2.54(0.18)$ & $2.70(1.15)$ \\
\hline Triglyceride, $\mathrm{mmol} / \mathrm{L}$ & $1.57(0.29)$ & $2.60(0.44)^{a}$ & $4.87(1.50)^{b}$ & $2.99(1.71)$ & $2.35(0.36)^{a}$ & $2.17(0.22)^{b}$ \\
\hline Apolipoprotein Al, g/L & $1.39(0.06)$ & $1.43(0.07)$ & $1.34(0.06)$ & $1.33(0.06)$ & $1.45(0.04) *$ & $1.32(0.04)$ \\
\hline Alanine aminotransferase, $\mu \mathrm{Kat} / \mathrm{L}$ & $0.52(0.10)$ & $0.57(0.11)$ & $0.45(0.06)$ & $1.16(0.16)$ & $0.91(0.11)$ & $0.69(0.07)^{a}$ \\
\hline Aspartate aminotransferase, $\mu \mathrm{Kat} / \mathrm{L}$ & $0.45(0.07)$ & $0.45(0.04)$ & $0.41(0.08)$ & $1.02(0.13)$ & $0.94(0.14)$ & $0.69(0.07)^{a}$ \\
\hline
\end{tabular}

Values are the mean and the standard error of the mean (S.E.M.).

HOMA-IR is homeostasis model assessment-estimated insulin resistance; NEFA indicates non-esterificated fatty acids; NNRTI: non-nucleoside analogues reverse transcriptase inhibitors; PI: protease inhibitors;

${ }^{\mathrm{a}} \mathrm{P}<0.05,{ }^{\mathrm{b}} \mathrm{P}<0.01$ and ${ }^{\mathrm{C}} \mathrm{P}<0.001$ vs untreated patients of the corresponding group; ${ }^{*} \mathrm{P}<0.05$ with respect to $\mathrm{Pl}$-treated patients in the corresponding group 


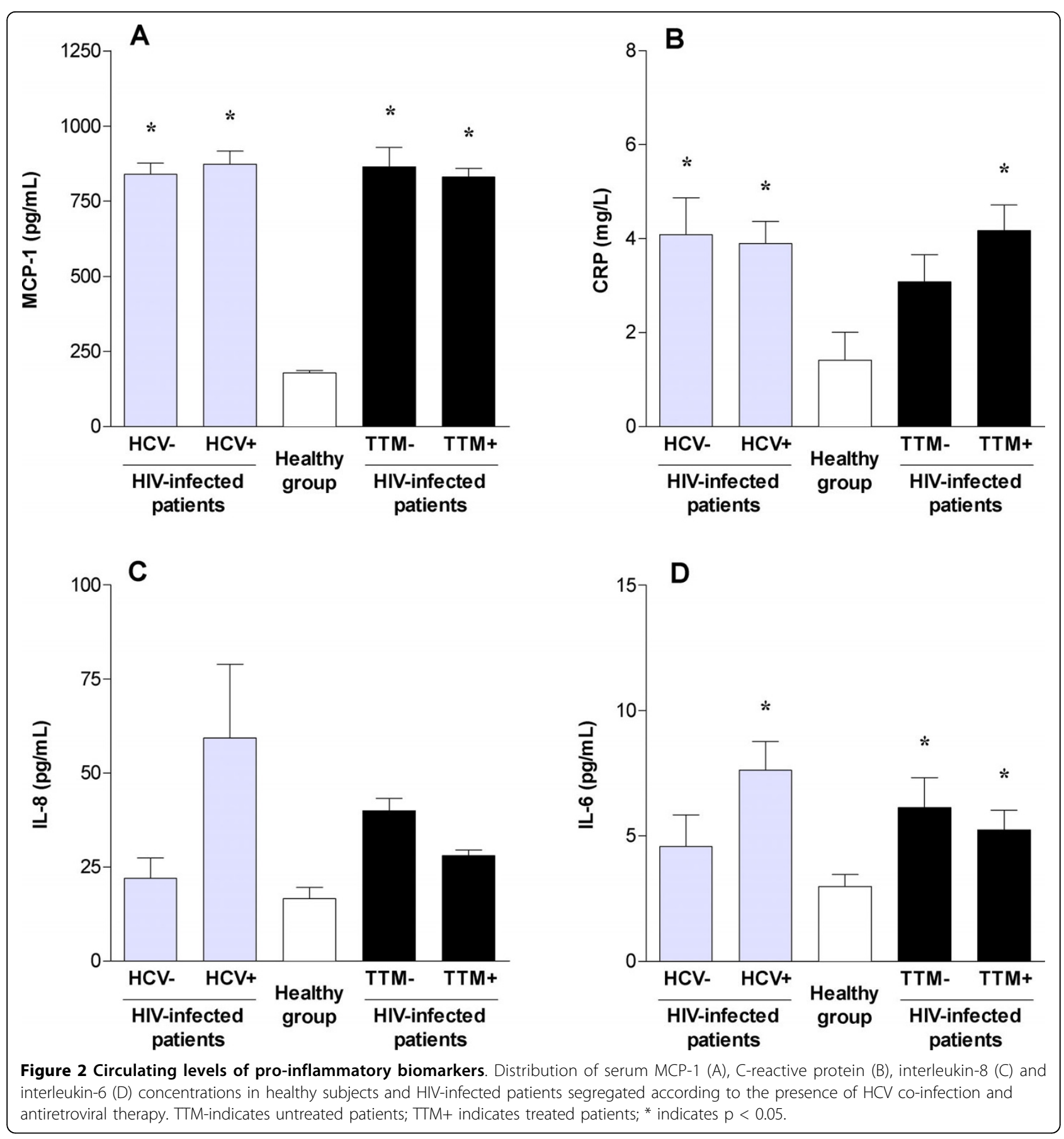

approach, it has been demonstrated that FASN is significantly up-regulated during both HIV infection and HCV infection $[4,5,7]$. Our data confirm and extend further these in vitro findings in a clinical setting revealing for the first time that HIV-infected patients show significant elevations in circulating serum FASN concentration with respect to healthy uninfected donors. Moreover, the increase in serum FASN concentration is even greater in HIV-patients co-infected with HCV. FASN, an intracellular protein, appears to exit cells during HIV infection and this release into the circulation is exacerbated in the presence of HCV co-infection, a condition that is frequently observed in HIV-infected patients. Based on the gender dependencies that we observed (i.e. women with undetectable HIV viral load or in those undergoing NNRTI-based antiretroviral regimen), and considering that women infected with HIV have a higher rate of gonadal dysfunction [19], it could be 


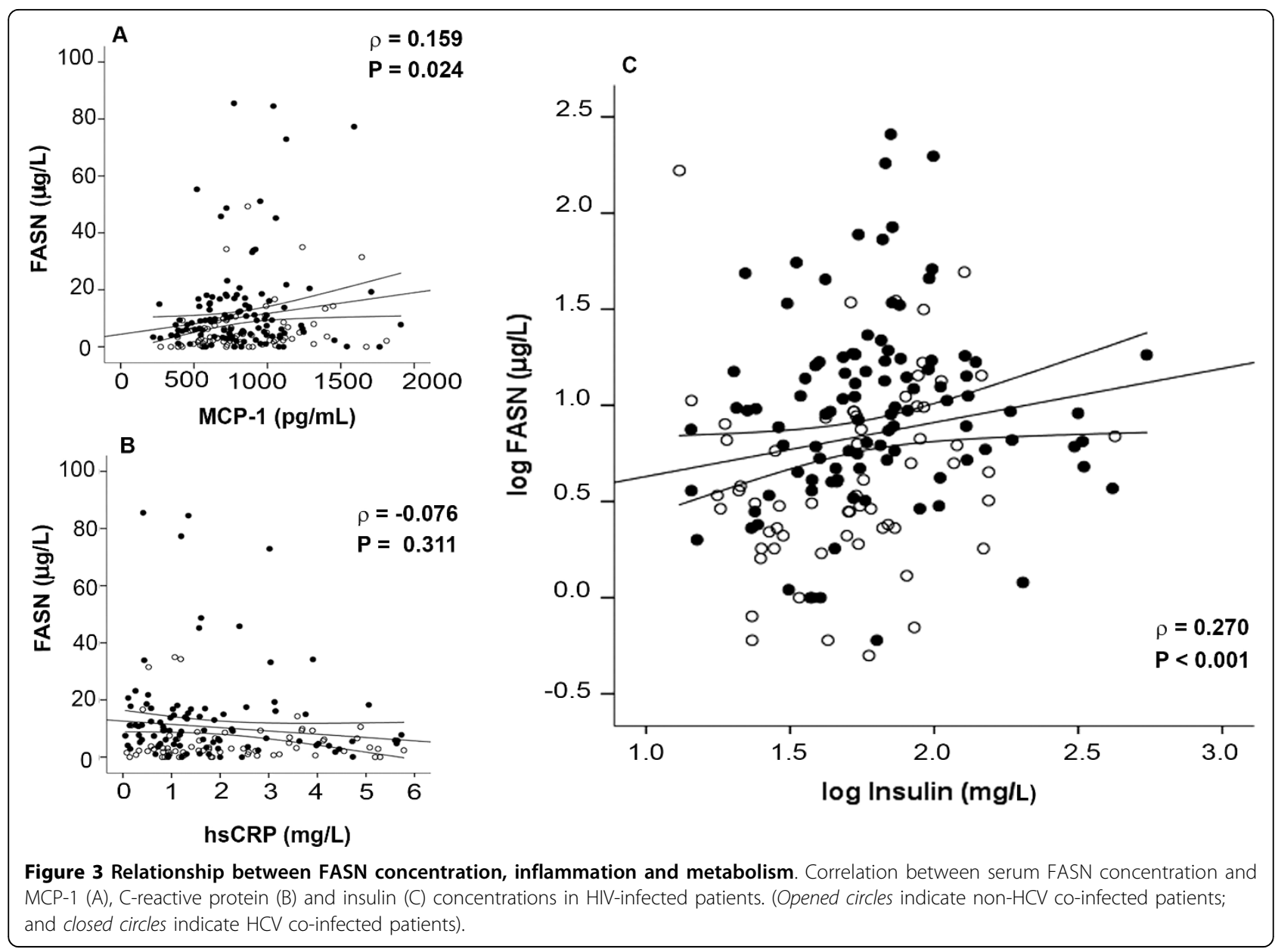

argued that enhanced levels of serum FASN might arise, at least in part, from stimulatory effects of estrogen on FASN gene expression which, in turn, will result in enhanced release of FASN protein [20-22]. Conversely, and perhaps surprisingly, we did not observe any significant relationship between circulating levels of the extracellular form of FASN and HIV-related dyslipidemia and lipodystrophy, two conditions in which enhanced endogenous fatty acid synthesis is closely linked to the accumulation of lipids and disproportionate distribution of tissue-associated fats. Although cytosolic FASN, by the coordinated action of its seven active sites, catalyzes all of the necessary reactions in the synthesis of palmitate [23-25], we failed also to identify statistically significant changes in serum NEFAs concentrations in both groups of HIV-infected patients, with and without HCV co-infection. Therefore, our findings support a model in which, upon infection with HIV and/or HCV, changes in circulating levels of extracellular FASN take place through molecular mechanisms likely unrelated to established pathways that regulate the intracellular FASN expression [9,10,23-25]. Notably, integration of
HIV into the host cell chromosome occurs preferentially within genes. Particularly, insulin receptor (IRS), 19p13.3-13.2, is one of the identified integration sites [26] and the knockdown of this gene results in a significant up-regulation of FASN [27]. It is plausible, therefore, that increased levels of serum FASN are not a mere epiphenomenon related to cell destruction and leakage but rather to a pathophysiologic response occurring during the viral infection.

In multivariate analysis, serum MCP-1, but not other inflammatory biomarkers, significantly contributed to explain serum FASN concentration in $\mathrm{HCV}$ co-infected patients despite the strong association with serum ALT activity and treatment regimen. This is not unexpected as we have already shown that serum MCP-1 concentration may be a reliable marker of inflammation in hepatic derangements in patients with chronic liver disease, a characteristic that is not shared by serum CRP concentration [28]. As previously described [29], HCV co-infection increased serum IL-8 levels with respect to healthy individuals. Surprisingly, our comparison did not reach statistically significance, suggesting that IL-8 liver 


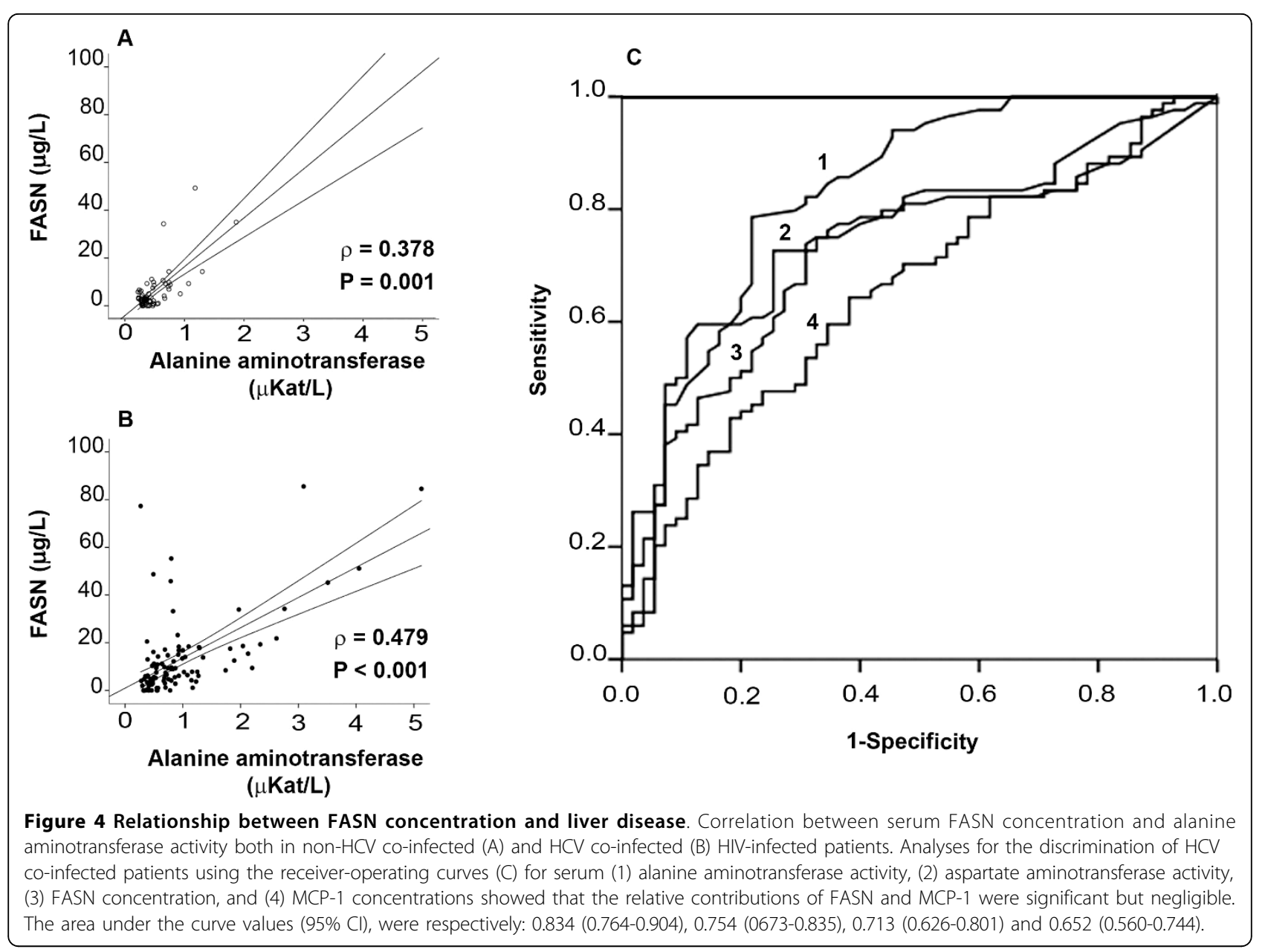

expression could be partially affected by antiretroviral HIV therapy as shown in Figure 2D. Moreover, the correlation between serum insulin and serum FASN was maintained irrespective of $\mathrm{HCV}$ co-infection or altered ALT values in HIV-infected patients.

Abnormalities of glucose regulation, including impaired glucose tolerance and insulin resistance, are often developed among HIV-infected patients, and coinfection with $\mathrm{HCV}$ appears to exacerbate insulin resistance in these patients [30-33]. Insulin resistance in this population may result from antiviral medication, effects of HIV and/or HCV per se, or from other indirect effects, such as fat redistribution. Considering that increased MCP-1 forms also a vicious adipokine network causing insulin resistance and metabolic syndrome [34], both the chronic viral state itself and the host immune response can give rise to glucose and lipid metabolic disorders which, in turn, are risk factors for hepatic damage. Therefore, it is tempting to suggest that molecular determinants of $\mathrm{HIV} / \mathrm{HCV}$ action on FASN release are closely linked to the overall metabolic regulation. In this scenario, increased concentrations of serum
FASN might universally occur in metabolic disorders in which insulin resistance could be prominent. Supporting this notion, we and others have found that serum FASN concentration is increased in patients with non-alcoholic steatohepatitis or chronic liver impairment $[35,36]$. We have also found higher concentrations of circulating FASN in patients with type 2 diabetes [9]. Administration of insulin sensitizers significantly prevented FASN release from cultured human adipose tissue explants whereas treatment with inflammatory stimuli increased the amount of extracellular FASN [9]. We now add chronic infection with $\mathrm{HIV} / \mathrm{HCV}$ as a novel pro-insulin resistance setting in which serum FASN concentration is significantly increased.

We have also provided experimental evidence to suggest that FASN release is an active and controlled process through the activation of AMP-activated protein kinase (AMPK) [15], a key enzyme that regulates the body energy balance [37-39]. We acknowledge that the ultimate mechanisms through which $\mathrm{HIV} / \mathrm{HCV}$ infections influence the FASN release cannot by addressed by our study but $\mathrm{HIV} / \mathrm{HCV}$-induced changes on AMPK 
Table 4 Multivariate analyses of the determinants of FASN concentrations in HCV co-infected patients $(n=115)$

\begin{tabular}{|c|c|c|c|}
\hline & $\begin{array}{c}\beta \\
\text { Coefficient }\end{array}$ & $95 \% \mathrm{Cl}$ & $\begin{array}{c}P \\
\text { Values }\end{array}$ \\
\hline Age, years & 0.144 & -0.409 to 1.327 & 0.292 \\
\hline Gender, male & 0.134 & -15.86 to 5.14 & 0.327 \\
\hline BMI, $\mathrm{kg} / \mathrm{m}^{2}$ & 0.086 & -0.75 to 1.677 & 0.444 \\
\hline $\begin{array}{l}\text { Patients treated with PI or } \\
\text { NNRTI, } n\end{array}$ & -0.295 & -23.92 to 1.56 & 0.041 \\
\hline Lipodystrophy, n & -0.202 & -18.147 to 2.19 & 0.121 \\
\hline CD4+ T cell count, cells $/ \mathrm{mm}^{3}$ & 0.121 & -0.005 to 0.19 & 0.260 \\
\hline $\begin{array}{l}\text { Undetectable HIV-1 viral } \\
\text { load }^{\mathrm{a}}, \mathrm{n}\end{array}$ & 0.053 & -6.559 to 10.55 & 0.639 \\
\hline HDL-cholesterol, mmol/L & 0.046 & -12.89 to 17.55 & 0.759 \\
\hline Triglyceride, $\mathrm{mmol} / \mathrm{L}$ & 0.050 & -2.45 to 3.49 & 0.726 \\
\hline Apolipoprotein A-I, g/L & 0.230 & -5.063 to 36.14 & 0.135 \\
\hline $\mathrm{MCP}-1, \mathrm{pg} / \mathrm{mL}$ & 0.271 & 2.403 to 0.021 & 0.021 \\
\hline Insulin, pmol/L & -0.009 & -0.040 to 0.037 & 0.937 \\
\hline IL-8, ng/L & 0.025 & -0.012 to 0.016 & 0.828 \\
\hline hsCRP, mg/L & -0.108 & -1.00 to 0.328 & 0.312 \\
\hline $\begin{array}{l}\text { Alanine aminotransferase, } \\
\mu \mathrm{Kat} / \mathrm{L}\end{array}$ & 0.599 & 5.154 to 18.48 & 0.001 \\
\hline $\begin{array}{l}\text { Aspartate aminotransferase, } \\
\mu \mathrm{Kat} / \mathrm{L}\end{array}$ & -0.073 & -9.98 to 6.36 & 0.668 \\
\hline
\end{tabular}

Dependent variable: FASN concentration ( $\mu \mathrm{g} / \mathrm{L})$

BMI: body-mass index; NNRTI: non-nucleoside analogues reverse transcriptase inhibitors; Pl: protease inhibitors, hsCRP: high sensitive C-reactive protein.

aLimit of detection was 40 copies $/ \mathrm{mL}$

function might play a pivotal role. HIV and $\mathrm{HCV}$ are slow-growing viruses that should maintain beneficial host cell functions for an extended period as signs of disease do not usually show up until months or years after initial exposure. This requires a strict control of cellular AMPK because intense response and energy utilization could be deleterious to the viral infection [40]. We hypothesize that upon AMPK activation, the extracellular release of excess FASN may provide a rapid mechanism to prevent further energy consumption. Conversely, if we assume that FASN up-regulation is important in the pathogenesis of HIV and HCV infection, as it has been already demonstrated in infections by the hepatitis B virus and the coxsackievirus B3 [41], it is conceivable that FASN might be a potential therapeutic target for an antiviral therapy.

\section{Conclusions}

Serum FASN concentration is significantly increased in HIV-infected patients. The release of the extracellular form of FASN into the circulation is further enhanced in patients who are co-infected with $\mathrm{HCV}$ or are not undergoing antiretroviral therapy. Subsequent studies should explore the usefulness of serum FASN concentration measurement to monitor the effects viral infections on disease progression and survival as well as the putative prognostic or diagnostic role for patients in whom repetitive viral infections and associated diseases are expected.

\section{Abbreviations \\ ALT: alanine aminotransferase; AMPK: AMP-activated protein kinase; BMI: body mass index; CRP: C-reactive protein; FASN: fatty acid synthase; HCV: hepatitis-C virus; IL-6: interleukin-6; IL-8: interleukin-8; MCP-1: monocyte chemoattractant protein-1; NEFAs: non-esterificated fatty acids; NNRTI: non- nucleoside reverse transcriptase inhibitors.}

\section{Acknowledgements \\ This work was supported in part by Instituto de Salud Carlos III (Ministerio de Sanidad y Consumo, Fondo de Investigación Sanitaria -FIS-, Spain, Grants CP05-00090, PI08-1032, PI06-0778 and RD06-0020-0028 to Javier A. Menendez). GA, AR and RB are the recipients of a grant from Comissionat per a Universitats i Recerca del Departament d'Innovació, Universitats i Empresa de la Generalitat de Catalunya i del Fons Social Europeu. JAM is the recipient of a Basic, Clinical and Translational Research Award (BCTR0600894) from the Susan G. Komen Breast Cancer Foundation (Texas, USA). JAM was also supported by a Grant from the Fundación Científica de la Asociación Española Contra el Cáncer (AECC, Spain). AVM is the recipient of a "Sara Borrell" post-doctoral contract (CD08/00283, Ministerio de Sanidad y Consumo, Fondo de Investigación Sanitaria -FIS-, Spain).}

\section{Author details}

${ }^{1}$ Centre de Recerca Biomèdica, Hospital Universitari de Sant Joan, Institut d'Investigació Sanitària Pere Virgili (IISPV), Universitat Rovira i Virgili, Reus, Spain. ${ }^{2}$ Servei de Medicina Interna, Hospital Son Llàtzer, Palma, Illes Balears, Spain. ${ }^{3}$ Catalan Institute of Oncology (ICO), Dr. Josep Trueta. University Hospital, Girona, Spain. ${ }^{4}$ Biomedical Research Institute (IdIBGi), Dr. Josep Trueta. University Hospital, Girona, Spain.

\section{Authors' contributions}

GA, CAV, JAM, and JJ drafted the manuscript, participated in the design and coordination of the study. GA, COF, RBD, AR and FRS performed

experimental procedures and collected data regarding HIV-infected patients. GA and CAV performed the statistical analysis. AVM and JC commented on the manuscript and participated in the design. All authors read and approved the final manuscript.

\section{Competing interests}

The authors declare that they have no competing interests.

Received: 9 December 2009 Accepted: 13 August 2010 Published: 13 August 2010

\section{References}

1. Monsuez JJ, Charniot JC, Escaut L, Teicher E, Wyplosz B, Couzigou C, Vignat N, Vittecoq D: HIV-associated vascular diseases: structural and functional changes, clinical implications. Int I Cardiol 2009, 133:293-306.

2. Fisher SD, Miller TL, Lipshultz SE: Impact of HIV and highly active antiretroviral therapy on leukocyte adhesion molecules, arterial inflammation, dyslipidemia, and atherosclerosis. Atherosclerosis 2006, 185:1-11.

3. Umpleby AM, Das S, Stolinski M, Shojaee-Moradie F, Jackson NC, Jefferson W, Crabtree N, Nightingale P, Shahmanesh M: Low density lipoprotein apolipoprotein B metabolism in treatment-naïve HIV patients and patients on antiretroviral therapy. Antivir Ther 2005, 10:663-670.

4. Chan EY, Qian WJ, Diamond DL, Liu T, Gritsenko MA, Monroe ME, Camp DG, Smith RD, Katze MG: Quantitative analysis of human immunodeficiency virus type 1-infected CD4+ cell proteome: dysregulated cell cycle progression and nuclear transport coincide with robust virus production. J Virol 2007, 81:7571-7583.

5. Rasheed S, Yan JS, Lau A, Chan AS: HIV replication enhances production of free fatty acids, low density lipoproteins and many key proteins involved in lipid metabolism: a proteomics study. PLOS ONE 2008, 3 e3003. 
6. Huang H, Sun F, Owen DM, Li W, Chen Y, Gale m Jr, Ye J: Hepatitis C virus production by human hepatocytes dependent on assembly and secretion of very low-density lipoproteins. PNAS 2007, 104:5848-5853.

7. Yang W, Hood BL, Chadwick SL, Liu S, Watkins SC, Luo G, Conrads TP, Wang T: Fatty acid synthase is up-regulated during hepatitis $C$ virus infection and regulates hepatitis $C$ virus entry and production. Hepatology 2008, 48:1396-1403.

8. Low E, Vogel M, Rockstroh J, Nelson M: Acute hepatitis C in HIV-positive individuals. AIDS Rev 2008, 10:245-253.

9. Menendez JA, Vazquez-Martin A, Ortega FJ, Fernandez-Real JM: Fatty acid synthase: association with insulin resistance, type 2 diabetes, and cancer. Clin Chem 2009, 55:425-38.

10. Menendez JA, Lupu R: Fatty acid synthase and the lipogenic phenotype in cancer pathogenesis. Nat Rev Cancer 2007, 7:763-777.

11. Wang Y, Kuhajda FP, Li JN, Pizer ES, Han WF, Sokoll LJ, Chan DW: Fatty acid Synthase (FAS) expression in human breast cancer cell culture supernatants and in breast cancer patients. Cancer Lett 2001, 167:99-104.

12. Wang Y, Kuhajda FP, Sokoll LJ, Chan DW: Two-site ELISA for the quantitative determination of fatty acid synthase. Clin Chim Acta 2001, 304:107-115

13. Wang YY, Kuhajda FP, Cheng P, Chee WY, Li T, Helzlsouer KJ, Sokoll LJ, Chan DW: A new model ELISA, based on two monoclonal antibodies, for quantification of fatty acid Synthase. J Immunoassay Immunochem 2002, 23:279-292.

14. Wang YY, Kuhajda FP, Li J, Finch TT, Cheng P, Koh C, Li T, Sokoll LJ, Chan DW: Fatty acid synthase as a tumor marker: its extracellular expression in human breast cancer. J Exp Ther Oncol 2004, 4:101-110.

15. Oliveras-Ferraros C, Vazquez-Martin A, Fernández-Real JM, Menendez JA: AMPK-sensed cellular energy state regulates the release of extracellular Fatty Acid Synthase. Biochem Biophys Res Commun 2009, 378:488-493.

16. Alonso-Villaverde C, Coll B, Parra S, Montero M, Calvo N, Tous M, Joven J, Masana L: Atherosclerosis in patients infected with HIV is influenced by a mutant monocyte chemoattractant protein-1 allele. Circulation 2004, 110:2204-2209.

17. Simó JM, Castellano I, Ferré N, Joven J, Camps J: Evaluation of a homogeneous assay for high-density lipoprotein cholesterol: limitations in patients with cardiovascular, renal, and hepatic disorders. Clin Chem 1998, 44:1233-1241.

18. Matas C, Cabré M, La Ville A, Prats E, Joven J, Turner PR, Masan L, Camps J: Limitations of the Friedewald formula for estimating low-density lipoprotein cholesterol in alcoholics with liver disease. Clin Chem 1994, 40:404-406.

19. Allred K, Smart EJ, Wilson ME: Estrogen receptor-alpha mediates gender differences in atherosclerosis induced by HIV protease inhibitors. J Biol Chem 2006, 281:1419-25.

20. Menendez JA, Oza BP, Atlas E, Verma VA, Mehmi I, Lupu R: Inhibition of tumor-associated fatty acid synthase activity antagonizes estradiol- and tamoxifen-induced agonist transactivation of estrogen receptor (ER) in human endometrial adenocarcinoma cells. Oncogene 2004, 23:4945-4958.

21. Menendez JA, Oza BP, Colomer R, Lupu R: The estrogenic activity of synthetic progestins in oral contraceptives enhances fatty acid synthasedependent breast cancer cell proliferation and survival. Int J Oncol 2005, 26:1507-1515.

22. Lupu R, Menendez JA: Targeting fatty acid synthase in breast and endometrial cancer: An alternative to selective estrogen receptor modulators? Endocrinology 2006, 147:4056-4066.

23. Menendez JA, Lupu R: Fatty acid synthase-catalyzed de novo fatty acid biosynthesis: from anabolic-energy-storage pathway in normal tissues to jack-of-all-trades in cancer cells. Arch Immunol Ther Exp (Warsz) 2004, 52:414-426.

24. Menendez JA, Lupu R: Oncogenic properties of the endogenous fatty acid metabolism: molecular pathology of fatty acid synthase in cancer cells. Curr Opin Clin Nutr Metab Care 2006, 9:346-357.

25. Lupu R, Menendez JA: Pharmacological inhibitors of Fatty Acid Synthase (FASN)-catalyzed endogenous fatty acid biogenesis: a new family of anti-cancer agents? Curr Pharm Biotechnol 2006, 7:483-493.

26. Liu H, Dow EC, Arora R, Kimata JT, Bull LM, Arduino RC, Rice AP: Integration of human immunodeficiency virus type 1 in untreated infection occurs preferentially within genes. J Virol 2006, 80:7765-7768.

27. Taniguchi CM, Ueki K, Kahn R: Complementary roles of IRS-1 and IRS-2 in the hepatic regulation of metabolism. J Clin Invest 2005, 115:718-727.
28. Marsillach J, Bertran N, Camps J, Ferré N, Riu F, Tous M, Coll B, AlonsoVillaverde $C$, Joven J: The role of circulating monocyte chemoattractant protein-1 as a marker of hepatic inflammation in patients with chronic liver disease. Clin Biochem 2005, 38:1138-1140.

29. Polyak SJ, Khabar KS, Rezeiq M, Gretch DR: Elevated levels of interleukin-8 in serum are associated with hepatitis $C$ virus infection and resistance to interferon therapy. J Virol 2001, 75:6209-6211.

30. Grinspoon S: Mechanisms and strategies for insulin resistance in acquired immune deficiency syndrome. Clin Infect Dis 2003, 37:85-90.

31. Aboud M, Elgalib A, Kulasegaram R, Peters B: Insulin resistance and HIV infection: a review. Int J Clin Pract 2007, 61:463-472.

32. Kotler DP: Hepatitis C, human immunodeficiency virus and metabolic syndrome: interactions. Liver Int 2009, 29:38-46.

33. Slama L, Le Camus C, Serfaty L, Pialoux G, Capeau J, Gharakhanian S: Metabolic disorders and chronic viral disease: the case of HIV and HCV. Diabetes Metab 2009, 35:1-11.

34. Yamauchi T, Kadowaki T: Physiological and pathophysiological roles of adiponectin and adiponectin receptors in the integrated regulation of metabolic and cardiovascular diseases. Int J Obes (Lond) 2008, 32:13-18.

35. Marsillach J, Oliveras-Ferraros C, Beltran R, Rull A, Aragonès G, AlonsoVillaverde C, Vázquez-Martín A, Joven J, Menéndez JA, Camps J: Serum concentrations of extracellular fatty acid synthase in patients with steatohepatitis. Clin Chem Lab Med 2009, 47:1097-1099.

36. Medghalchi SM, Vadlamudi A, Kuhajda FP: Fatty acid synthase phosphorylation as a cancer biomarker [abstract]. Proc Am Assoc Cancer Res 2009, 1580.

37. Hardie DG: AMPK: a key regulator of energy balance in the single cell and the whole organism. Int J Obes (Lond) 2008, 32:7-12.

38. Lage R, Diéguez C, Vidal-Puig A, López M: AMPK: a metabolic gauge regulating whole-body energy homeostasis. Trends Mol Med 2008, 14:539-549.

39. Towler MC, Hardie DG: AMP-activated protein kinase in metabolic control and insulin signaling. Circ Res 2007, 100:328-41.

40. Kudchodkar SB, Del Prete GQ, Maguire TG, Alwine JC: AMPK-mediated inhibition of mTOR kinase is circumvented during immediate-early times of human cytomegalovirus infection. J Virol 2007, 81:3649-3651.

41. Foo NC, Yen TS: Activation of promoters for cellular lipogenic genes by hepatitis B virus large surface protein. Virology 2000, 269:420-425.

\section{Pre-publication history}

The pre-publication history for this paper can be accessed here: http://www.biomedcentral.com/1471-230X/10/92/prepub

\section{doi:10.1186/1471-230X-10-92}

Cite this article as: Aragonès et al:: Infection with HIV and HCV enhances the release of fatty acid synthase into circulation: evidence for a novel indicator of viral infection. BMC Gastroenterology 2010 10:92.

\section{Submit your next manuscript to BioMed Central and take full advantage of:}

- Convenient online submission

- Thorough peer review

- No space constraints or color figure charges

- Immediate publication on acceptance

- Inclusion in PubMed, CAS, Scopus and Google Scholar

- Research which is freely available for redistribution

Submit your manuscript at www.biomedcentral.com/submit
C Biomed Central 